\title{
DIFFERENTIAL LEUCOCYTIC RESPONSES TO SPERMATOZOA IN THE CERVIX AND THE UTERUS IN EWES
}

\author{
P. E. MATTNER* \\ Physiology Department, National Institute for Research in Dairying, \\ Shinfield, Reading
}

(Received 15th March 1968)

\begin{abstract}
Summary. The effect of spermatozoa within the cervix and of spermatozoa within the uterus on the infiltration of polymorphonuclear leucocytes (polymorphs) into the lumen of the genital tract at oestrus was examined in ewes. Ligation of the cranial end of the cervix resulted in an accumulation of polymorphs in the lumen of the uterus and of fewer polymorphs in the lumen of the cervix. In genital tracts so ligated, spermatozoa within either the cervix or the uterus had no material effect on the number of polymorphs found in the cervix. The presence of spermatozoa in ligated uterine horns caused an increase in the number of polymorphs migrating into the lumina of the horns, the response being manifest within $5 \mathrm{hr}$. The results indicate that drainage of polymorphs from the uterus into and through the cervix is a normal occurrence in ruminants which may reduce the incidence of phagocytosis of spermatozoa in the uterus.
\end{abstract}

\section{INTRODUCTION}

In small laboratory animals, the presence of spermatozoa in the female genital tract does not have a strong stimulatory effect on the migration of leucocytes into the lumen of the uterus until after ovulation has occurred (McDonald, Black, McNutt \& Casida, 1952; Austin, 1957; Yanagimachi \& Chang, 1963). The same may not be true in ruminants. Mating of goats does result in greater numbers of leucocytes in the uterus and cervix at about the time of ovulation (Mattner, 1968), but Howe \& Black (1963) found that a marked increase in the number of leucocytes entering the vagina occurred within 4 to $8 \mathrm{hr}$ after insemination in hormone-treated, prepuberal calves. However, neither of the latter studies revealed whether the leucocytic response to spermatozoa was rapid enough for phagocytosis of spermatozoa by the leucocytes to reduce the number of spermatozoa in the uterus (thus the number of spermatozoa passing to the Fallopian tubes) before ovulation.

* Present address: Division of Animal Physiology, C.S.I.R.O., Ian Clunies Ross Animal Research Laboratory, Prospect, New South Wales, Australia. 
In hamsters in which the uterine horns had been ligated near the cervix, Yanagimachi \& Chang (1963) found that mating with a fertile male had no effect on the number of leucocytes entering the lumina of the horns. However, in ruminants, the cervix is a relatively large and highly developed structure in which are located the majority of the spermatozoa that remain in the genital tract after mating. Thus, it is possible that spermatozoa in either the uterus or the cervix might stimulate the migration of leucocytes into the uterus in ruminants.

Studies on these aspects in sheep are presented in this paper.

\section{MATERIALS AND METHODS}

Thirty parous Herdwick ewes, aged 3 to 5 years were used in two experiments during the normal breeding season. To facilitate operational procedure, oestrus was controlled by administering $10 \mathrm{mg}$ of progesterone in oily solution i.m. daily for 10 days and 800 i.u. pregnant mare serum gonadotrophin given s.c. $24 \mathrm{hr}$ after the last injection of progesterone. Oestrus was detected using an aproned ram.

Ram semen was obtained by electro-ejaculation. For intra-uterine inseminations, the semen was collected aseptically as follows. The glans and urethral process of the penis were washed with sterile saline and dried with sterile gauze. After the first portion of the ejaculate had been produced, the glans and urethral process were washed and dried as before and the final portion of the ejaculate was then collected with only the urethral process contained within a sterile collecting tube. The semen was held at $36^{\circ} \mathrm{G}$ and was diluted with sterile saline immediately before use.

Laparotomy, ligation of the genital tracts and uterine inseminations were performed while the ewes were under cyclopropane anaesthesia. When intrauterine inseminations were performed, each uterine horn was ligated near the junction of the horn with the body of the uterus and a second ligature was placed loosely around the horn near the utero-tubal junction. A 26-gauge hypodermic needle was inserted through the wall of each horn of the uterus near its apex and either a suspension of spermatozoa or sterile saline was injected into the lumen with a micro-syringe. The second ligature was tied firmly about $0.5 \mathrm{~cm}$ caudal to the site of puncture as the needle was withdrawn.

The methods used for recovery and flushing of the genital tracts and assessment of the numbers of polymorphonuclear leucocytes (polymorphs) in the lumina and the endometrial stroma of the genital tracts have been described previously (Mattner, 1968).

Data were converted on the $\log _{10}$ scale to give homogeneous variability and were analysed by analysis of variance.

\section{Experiment 1}

The cervix was ligated at the cranial end in each of ten ewes as soon as possible after commencement of oestrus. Five of these ewes were inseminated approximately $1 \mathrm{hr}$ later by flooding $0.5 \mathrm{ml}$ of freshly collected ram semen over the external orifice of the cervix. The genital tracts of the ten ewes were removed 
$25 \mathrm{hr}$ post-operatively. The genital tracts of five control ewes which received no treatment were removed $25 \mathrm{hr}$ after commencement of oestrus.

\section{Experiment 2}

The cranial and caudal extremities of each uterine horn were ligated in fifteen ewes during early oestrus. In each ewe, twenty million spermatozoa in $0.2 \mathrm{ml}$ containing 500 i.u. crystalline penicillin and 500 i.u. streptomycin per $\mathrm{ml}$ were injected into the lumen of one horn and $0.2 \mathrm{ml}$ of sterile saline containing similar concentrations of penicillin and streptomycin was injected into the lumen of the other horn. The genital tracts were removed from five ewes at 5 , 15 and $25 \mathrm{hr}$ after this procedure.

\section{RESULTS}

\section{Experiment 1}

Ovulation of at least one egg had occurred shortly before recovery of the genital tracts in three control ewes and in four ewes from each group in which

TABLE 1

THE EFFEGT OF LIGATION OF THE GRANIAL END OF THE CERVIX AND OF SPERMATOZOA IN THE GERVIX ON THE NUMBER OF LUMINAL POLYMORPHONUGLEAR LEUCOGYTES IN THE CERVIX AND THE UTERUS IN SHEEP

\begin{tabular}{|c|c|c|c|c|c|}
\hline & \multirow[b]{2}{*}{$\begin{array}{l}\text { Treatment } \\
\text { of ewes }\end{array}$} & \multicolumn{2}{|c|}{ Cervix } & \multicolumn{2}{|c|}{ Uterus } \\
\hline & & $\begin{array}{c}\text { Mean } \log _{10} \text { no. } \\
\text { polymorphs } \\
\text { (with antilog) }\end{array}$ & $\begin{array}{c}\text { Difference } \\
\text { between } \\
\text { means }\end{array}$ & $\begin{array}{c}\text { Mean } \log _{10} \text { no. } \\
\text { polymorphs } \\
\text { (with antilog) }\end{array}$ & $\begin{array}{c}\text { Difference } \\
\text { between } \\
\text { means }\end{array}$ \\
\hline A. & Nil & $\begin{array}{c}5 \cdot 178 \\
(151,000)\end{array}$ & $\mathrm{A}-\mathrm{B}, 1 \cdot 027^{* * *}$ & $\begin{array}{c}5.808 \\
\left(0.64 \times 10^{6}\right)\end{array}$ & $\mathrm{A}-\mathrm{B},-0.748^{* *}$ \\
\hline B. & Cervix ligated & $\begin{array}{c}4 \cdot 151 \\
(14,000)\end{array}$ & A-C, $1 \cdot 386^{* * *}$ & $\begin{array}{c}6.556 \\
\left(3.60 \times 10^{6}\right)\end{array}$ & $A-C,-0.700^{* *}$ \\
\hline C. & $\begin{array}{l}\text { Cervix ligated } \\
\text { + vaginal } \\
\text { insemination }\end{array}$ & $\begin{array}{c}3.792 \\
(6000)\end{array}$ & B-C, $0.359^{\text {N.S. }}$ & $\begin{array}{c}6.508 \\
\left(3.22 \times 10^{6}\right)\end{array}$ & B-C, $0.048^{\text {N.S. }}$ \\
\hline
\end{tabular}

All means based on five ewes.

S.E. of difference between means $=0 \cdot 205$, d.f. $=12$.

N.S., difference not significant; $* *$ difference significant, $P<0.01$; $* *$ difference significant, $P<0.001$.

the cervix had been ligated. In each of the remaining ewes, there was at least one large preovulatory follicle.

The mean $\log _{10}$ numbers of polymorphs recovered from the lumina of the cervices and uteri of the ewes from the three groups are shown in Table 1. For both groups of ewes in which the cervix had been ligated, the number of polymorphs in the lumen of the cervix was considerably lower than that for the ewes in the untreated group $(P<0.001)$. On the other hand, in both groups of ewes in which the ligation had been performed, the number of polymorphs in the lumen of the uterus was greater than the number in the uteri of the untreated ewes $(P<0.01)$. 
When the cervices of the ewes that had been inseminated were examined, live spermatozoa were present in all instances. The mean number of spermatozoa flushed from the cervices of these ewes was 290,000 (S.E. 57,000), and 53 (S.E. 5$) \%$ of these were motile. Insemination did not have any significant effect on the number of polymorphs in the lumen of either the cervix or the uterus in ewes in which the cervix had been ligated (see Table 1).

To verify that ligation of the cervix had not influenced the numbers of polymorphs infiltrating from the vascular system into the endometrial stroma of the cervices and uteri, and thus the number appearing in the lumina of these organs, the numbers of polymorphs in the cervical and uterine endometrial stroma of the ewes in all three groups were determined. There was no significant

TABLE 2

THE EFFEGT OF LIGATION OF THE GRANIAL END OF THE GERVIX AND OF SPERMATOZOA IN THE CERVIX ON THE NUMBER OF POLYMORPHONUGLEAR LEUCOCYTES IN THE ENDOMETRIAL STROMA OF THE GERVIX AND UTERUS IN SHEEP

\begin{tabular}{|c|c|c|c|c|c|}
\hline & \multirow[b]{2}{*}{$\begin{array}{l}\text { Treatment } \\
\text { of ewes }\end{array}$} & \multicolumn{2}{|c|}{ Cervix } & \multicolumn{2}{|c|}{ Uterus } \\
\hline & & $\begin{array}{c}\text { Mean } \log _{10} \text { no. } \\
\text { polymorphs } \\
\text { (with antilog) }\end{array}$ & $\begin{array}{l}\text { Difference } \\
\text { between } \\
\text { means }\end{array}$ & $\begin{array}{c}\text { Mean } \log _{10} \text { no. } \\
\text { polymorphs } \\
\text { (with antilog) }\end{array}$ & $\begin{array}{c}\text { Difference } \\
\text { between } \\
\text { means }\end{array}$ \\
\hline A. & Nil & $\begin{array}{c}5.412 \\
\left(0.61 \times 10^{6}\right)\end{array}$ & A-B, $0.034^{\text {N.s. }}$ & $\begin{array}{c}7.484 \\
\left(6.85 \times 10^{6}\right)\end{array}$ & $\mathrm{A}-\mathrm{B},-0.056^{\mathrm{N} . \mathrm{S}}$ \\
\hline B. & Cervix ligated & $\begin{array}{c}5.378 \\
\left(0.58 \times 10^{6}\right)\end{array}$ & A-C, $-0.044^{\text {N.s. }}$ & $\begin{array}{c}7.540 \\
\left(7 \cdot 32 \times 10^{6}\right)\end{array}$ & $\mathrm{A}-\mathrm{G},-0.037^{\mathrm{N} . \mathrm{s}}$ \\
\hline C. & $\begin{array}{l}\text { Cervix ligated } \\
+ \text { vaginal } \\
\text { insemination }\end{array}$ & $\begin{array}{c}5.456 \\
\left(0.66 \times 10^{6}\right)\end{array}$ & B-C, $-0.078^{\text {N.s. }}$ & $\begin{array}{c}7.521 \\
\left(7 \cdot 17 \times 10^{6}\right)\end{array}$ & B-C, $0.019^{\text {N.s. }}$ \\
\hline
\end{tabular}

All means based on five ewes.

S.E. of difference between means $=0 \cdot 197$, d.f. $=12$.

N.S., difference not significant.

difference between any of the three groups of ewes in the number of polymorphs in the endometrial stroma in either the cervix or the uterus (see Table 2).

\section{Experiment 2}

None of the five ewes examined at $5 \mathrm{hr}$, and only one of the five ewes examined $15 \mathrm{hr}$ post-operatively, had ovulated. At $25 \mathrm{hr}$, four of the five ewes had ovulated at least one egg and the ovaries of the remaining animal contained large preovulatory follicles.

At each of the three examination times, a proportion of the polymorphs flushed from the spermatozoa-injected uterine horns contained engulfed spermatozoa. The mean percentages $( \pm$ S.E.) of the polymorphs that contained spermatozoa at 5,15 and $25 \mathrm{hr}$ were $22 \pm 4,20 \pm 3$ and $28 \pm 5 \%$, respectively.

There was a progressive and highly significant increase in the number of luminal polymorphs with time in the spermatozoa-injected and the salineinjected uterine horns, but the number of luminal polymorphs was greater in the former than in the latter horn in four of five ewes at $5 \mathrm{hr}$, and in all five ewes at both 15 and $25 \mathrm{hr}$ post-operatively. Analyses showed that the difference 
between the mean $\log _{10}$ numbers of luminal polymorphs in the differently treated horns was significant at each examination time (see Table 3).

There was also an increase, with time, in the number of polymorphs in the endometrial stroma in each group of uterine horns. The mean $\log _{10}$ numbers (with antilog) of 'stromal' polymorphs at 5,15 and $25 \mathrm{hr}$ were $7 \cdot 109$ (12.8 million), 7.242 ( 17.5 million) and 7.324 (21.1 million), respectively, for the spermatozoa-injected horns, and 7.082 (12.1 million), 7.118 (13.1 million) and 7.207 (16.1 million), respectively, for the saline-injected horns. However, neither of the increases in the number of polymorphs in either group of horns, nor the difference between the mean $\log _{10}$ numbers in the two groups of horns at 5,15 or $25 \mathrm{hr}$ was significant $(P>0.05)$.

A difference between spermatozoa-injected and saline-injected uterine horns was found, however, when the total number of polymorphs (luminal and stromal) or the percentage of the total numbers of polymorphs present in the

TABLE 3

THE EFFECT OF SPERMATOZOA IN LIGATED UTERINE HORNS OF EWES ON THE NUMBER OF LUMINAL POLYMORPHONUGLEAR LEUCOCYTES

\begin{tabular}{l|c|c|c}
\hline \multirow{2}{*}{ Treatment of horn } & \multicolumn{3}{|c}{ Mean $\log _{10}$ no. of polymorphs (with antilog) at: } \\
\cline { 2 - 4 } & $5 \mathrm{hr}$ & $15 \mathrm{hr}$ & $25 \mathrm{hr}$ \\
\hline Spermatozoa and & $5 \cdot 653$ & $6 \cdot 773$ & 6.962 \\
saline introduced & $\left(0.45 \times 10^{6}\right)$ & $\left(5 \cdot 93 \times 10^{6}\right)$ & $\left(9 \cdot 16 \times 10^{6}\right)$ \\
Saline introduced & $5 \cdot 200$ & $6 \cdot 364$ & 6.458 \\
& $\left(0 \cdot 16 \times 10^{6}\right)$ & $\left(2 \cdot 31 \times 10^{6}\right)$ & $\left(2 \cdot 87 \times 10^{6}\right)$ \\
Difference between & $0 \cdot 453^{* *}$ & $0 \cdot 409^{* *}$ & $0.504^{* * *}$ \\
means & & & \\
\hline
\end{tabular}

All means based on five horns.

S.E. of difference between means $=0 \cdot 109$, d.f. $=12$.

$* *$ Difference significant, $P<0.01$; *** difference significant, $P<0.001$.

lumen at either 15 or $25 \mathrm{hr}$ post-operatively was considered. The mean $\log _{10}$ values (with antilog) for the total numbers of polymorphs in spermatozoainjected and saline-injected horns were 7.373 (23.6 million) and 7.195 (15.7 million), respectively, at $15 \mathrm{hr}$ and were 7.488 (30.8 million) and 7.286 (19.3 million), respectively, at $25 \mathrm{hr}$. At each of these times, the difference between the means was significant (S.E. of difference $=0.073$, d.f. $=8, P<0.05$ ). The mean percentages $( \pm$ S.E. $)$ of the total numbers of polymorphs in the lumina of the spermatozoa-injected horns and the saline-injected horns were $25 \cdot 8 \pm 2 \cdot 9$ and $16.0 \pm 2.9 \%$, respectively, at $15 \mathrm{hr}$, and $31 \cdot 0 \pm 4 \cdot 4$ and $16 \cdot 6 \pm 3.6 \%$, respectively, at $25 \mathrm{hr}$. Using analysis of variance, the difference between the means at $15 \mathrm{hr}$ fell just short of significance at the $5 \%$ level but the difference between the means at $25 \mathrm{hr}$ was significant (S.E. of difference $=4.5$, d.f. $=8$, $P<0 \cdot 05)$.

\section{DISGUSSION}

Results obtained in the present study support the conclusion that, in ruminants, the majority of the polymorphs that are found in the lumen of the cervix during 
oestrus have come from the lumen of the uterus (Mattner, 1968). Although similar numbers of polymorphs were present in the endometrial stroma of the ligated and unligated cervices of ewes at about the end of oestrus, the number of luminal polymorphs in the cervices of the ewes in which the cranial end of the cervix had been ligated was extremely small compared with the number in the cervices of the control ewes. At the same time, the number of polymorphs in the uterine lumina was greater in the former than in the latter ewes and this could only be ascribed to the effect of the ligation of the cervix in preventing the escape of polymorphs from the lumen of the uterus to that of the cervix.

It was found, in ewes, that a stimulatory effect of spermatozoa on the migration of polymorphs into the lumen of the uterus only occurs, as in the hamster (Yanagimachi \& Ghang, 1963), when spermatozoa are in the uterus. The presence of spermatozoa in the cervix and vagina had no effect on the migration of polymorphs into the lumen of the uterus or the cervix. In ewes, the majority of spermatozoa that are retained in the genital tract after mating are located in the cervix, these forming the spermatozoan reserve (Quinlan, Maré \& Roux, 1932; Mattner, 1963). Thus, the establishment of the spermatozoan reserve in the cervix in the ewe may help to reduce the incidence of phagocytosis of spermatozoa in the uterus by minimizing the stimulus to the migration of leucocytes into the uterus.

In small laboratory animals, the presence of spermatozoa in the uterine horns does not materially increase the number of leucocytes entering the lumen of the horns until late oestrus or metoestrus (McDonald et al., 1952; Austin, 1957; Yanagimachi \& Chang, 1963). However, the leucocytic response to spermatozoa in the uterine horns in sheep occurred during early oestrus and was evident within $5 \mathrm{hr}$ of the introduction of spermatozoa. The leucocytic response observed in the present study may be greater, quantitatively, than would normally occur, for the number of spermatozoa introduced into the uterine horns was far greater than the numbers that are found in the uterus of the ewe at any time after mating (Mattner, 1963). Nevertheless, as polymorphs in mucus obtained from cervices of cows will engulf motile spermatozoa in vitro (Mattner, 1966), the rapidity of the response should militate against the survival of spermatozoa in the uterus and reduce the number of spermatozoa entering the Fallopian tubes. However, it appears from the present and previous studies (Mattner, 1968) that the passage or drainage of polymorphs from the lumen of the uterus to that of the cervix is a normal phenomenon in ruminants which would tend to reduce spermatozoan mortality in the uterus.

The foregoing also re-emphasizes the physiological significance of the spatial separation of the polymorph and spermatozoan population which occurs in the cervix in ruminants (Mattner, 1968). Thus, drainage of polymorphs from the lumen of the uterus can be effected by way of the cervical lumen with little consequence to the reserve of spermatozoa established in the cervix.

\section{AGKNOWLEDGMENTS}

I wish to thank Mrs J. Rose for skilled technical assistance, Mr A. Turvey for histological work, Messrs D. R. Westgarth and M. R. Jones for advice and 
statistical analyses, and the A.R.C. Institute for Research into Animal Diseases for making sheep available.

This work forms part of a programme financed by the Population Council, Rockefeller University, New York, whose support is gratefully acknowledged.

\section{REFERENCES}

Austin, C. R. (1957) Fate of spermatozoa in the uterus of the mouse and rat. F. Endocr. 14, 335.

Howe, G. R. \& BLACK, D. L. (1963) Spermatozoan transport and leucocytic responses in the reproductive tract of calves. F. Reprod. Fert. 6, 305.

MaDonald, L. E., Black, W. G., McNurt, S. H. \& Casida, L. E. (1952) The response of the rabbit uterus to instillation of semen at different phases of the estrous cycle. Am. J. vet. Res. 13, 419.

Matrner, P. E. (1963) Spermatozoa in the genital tract of the ewe. II. Distribution after coitus. Aust. F. biol. Sci. 16, 688.

Mattner, P. E. (1966) The cervix and its secretion in relation to fertility in ruminants. Ph.D. thesis, University of Reading.

MATtNeR, P. E. (1968) The distribution of spermatozoa and leucocytes in the female genital tract in goats and cattle. 7. Reprod. Fert. 17, 253.

Quinlan, J., Mark, G. S. \& Roux, L. L. (1932) The viability of the spermatozoa in the genital tract of the Merino ewe, with special reference to its practical application in breeding. Rep. vet. Res. Un. S. Afr. 18, 831 .

YanaGimachi, R. \& Chang, M. C. (1963) Infiltration of leucocytes into the lumen of the golden hamster during the oestrous cycle and following mating. F. Reprod. Fert. 5, 389. 